\title{
Studies on a novel series of $3(2 H)$-pyridazinones: Synthesis, molecular modelling, antimicrobial activity
}

\author{
Zeynep ÖZDEMİR 1 * (D), Mehmet Abdullah ALAGÖZ ${ }^{1}$ (D) , Alp Giray AKDEMİR ${ }^{2}$ (D), \\ Azime Berna ÖZÇELIKK ${ }^{2}$ iD, Berrin ÖZÇELİK ${ }^{3}$ (D), Mehtap UYSAL 2 (D) \\ 1 Department of Pharmaceutical Chemistry, Faculty of Pharmacy, İnönü University, Malatya, Turkey \\ 2 Department of Pharmaceutical Chemistry, Faculty of Pharmacy, Gazi University, Ankara, Turkey \\ 3 Department of Pharmaceutical Microbiology, Faculty of Pharmacy, Gazi University, Ankara, Turkey \\ * Corresponding Author. E-mail: zeynep.bulut@inonu.edu.tr (Z.Ö.); Tel. +90-422-341 0660.
}

Received: 01 February 2019 / Revised: 01 August 2019 / Accepted: 02 August 2019

\begin{abstract}
Efforts to develop new potent and effective antimicrobial compounds with lower side effects are important not only for controlling serious infections but also for cancer, surgical operations, and preventing possible infections which are related to other threats. Therefore, it is getting more important to develop new antibacterial and antifungal compounds with wide spectrum, systemic effect and lower side effects. In this study eight new $3(2 H)$ pyridazinone derivatives were synthesized and their antimicrobial activities were evaluated by using broth microdilution method agains two Gr (+) (Staphylococcus aureus, Enterococcus faecalis), two Gr (-) bacteria (Pseudomonas aeruginosa, Escherichia coli) and three yeasts like fungi (Candida albicans, Candida krusei). Compound $\mathbf{D}_{2 \mathrm{a}}$ had the best antibacterial activity among the synthesized compounds. All compounds were more effective against the fungus than the bacteria. In this study, we performed molecular modelling studies to provide in depth understanding of their CYP51 inhibition. Antifungal susceptibility tests against standard Candida spp. including C. albicans revealed $\mathbf{D}_{2 a}$ as highly active compound. The molecular docking studies showed similarities in binding interactions in active site gorges of the enzymes with known inhibitors, such as VT1, fluconazole.
\end{abstract}

KEYWORDS: 3(2H)-Pyridazinones; antibacterial; antifungal; antimicrobial; molecular modelling.

\section{INTRODUCTION}

Studies to develop a potent and effective antimicrobial compound are important not only for the control of serious infections, but also for the prevention and treatment of possible infections due to other treatments such as cancer, surgical procedures. Fungal infections increase in the suppression of immune system such as tuberculosis, cancer, AIDS and organ transplantation and it can be the cause of death [1-3]. For these reasons, the development of antifungal compounds with a broad spectrum of activity, minimized side effects is an important issue.

Hospital infections continue to be the focus of attention due to social problems brought along with mortality, morbidity and cost increases. Hospital infections occur in 5 to $10 \%$ of hospital admissions, most commonly in the form of urinary tract infection, surgical site infection, respiratory infection and bacteremia. Bacteremia is an important group in nosocomial infections [4,5]. Despite the advances in antibiotic therapy and all the improvements in intensive care conditions, mortality is still high and varies between $18-50 \%$. In recent years, although the incidence of gram-negative bacteria has been reported to be low among nosocomial bacteremia factors, it still remains important [6].

Among the pharmacophore groups which is responsible for antimicrobial activity, the $3(2 H)$ pyridazinone skeleton is one of the important structures used in the synthesis of more effective and broad spectrum antimicrobials [7-14].

Budhlakoti et al. performed the synthesis of a new series of pyridazin-3-one derivative compounds and evaluated their antibacterial activity by in vitro disk diffusion method. They reported that the compounds which are obtained by them, 4-benzylidene-6-phenyl-4,5-dihydropyridazin-3(2H)-one and 4-benzylidene-6(4-chlorophenyl)-4,5-dihydropyridazin-3(2H)-one, showed good antimicrobial activity against $S$. aureus and S. epidermidis. It is also reported that the other compounds, 4-(4-chlorobenzylidene)-6-phenyl-4,5-

How to cite this article: Özdemir Z, Alagöz MA, Akdemir AG, Özçelik AB, Özçelik B, Uysal M. Studies on a novel series of 3(2H)-pyridazinones: Synthesis, molecular modelling, antimicrobial activity. J Res Pharm. 2019; 23(5): 960-972. 
dihydropyridazin-3(2H)-one and 4-(4-methoxybenzylidene)-6-(4-chlorophenyl)-4,5-dihydropyridazin-3(2H)one showed good antimicrobial activity against P. euroginosa and E. coli [9] (Figure 1).

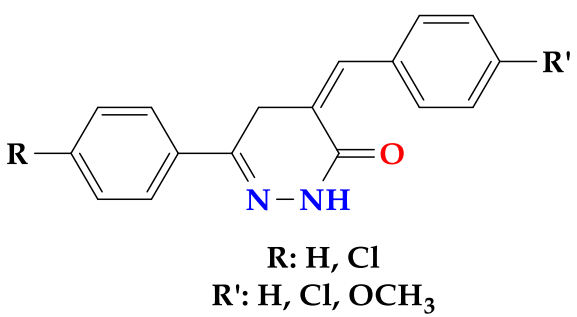

Figure 1. Structure of 4-substituted pyridazinones.

In another study, a series of new compounds containing $N$ '-benzylidene-acetohydrazide group in the second position of $3(2 \mathrm{H})$-pyridazinone ring have been investigated, the antibacterial, antifungal and antimycobacterial activities of the compounds evaluated. It is reported that 2-[4-(4-chlorophenyl)-6(morpholin-4-yl)-3-oxo-(2H)-pyridazin-2-yl]- $N^{\prime}$-(4-tert-butylbenzylidene) acetohydrazide and 2-[4-(4chlorophenyl)-6-(morpholine)-4-yl)-3-oxo-(2H)-pyridazin-2-yl]-N'-(4-chlorobenzylidene) acetohydrazide is effective against both Gram (+) and Gram (-) bacteria and most of the synthesized compounds are active against E. coli (ATCC 35218) [10] (Figure 2).
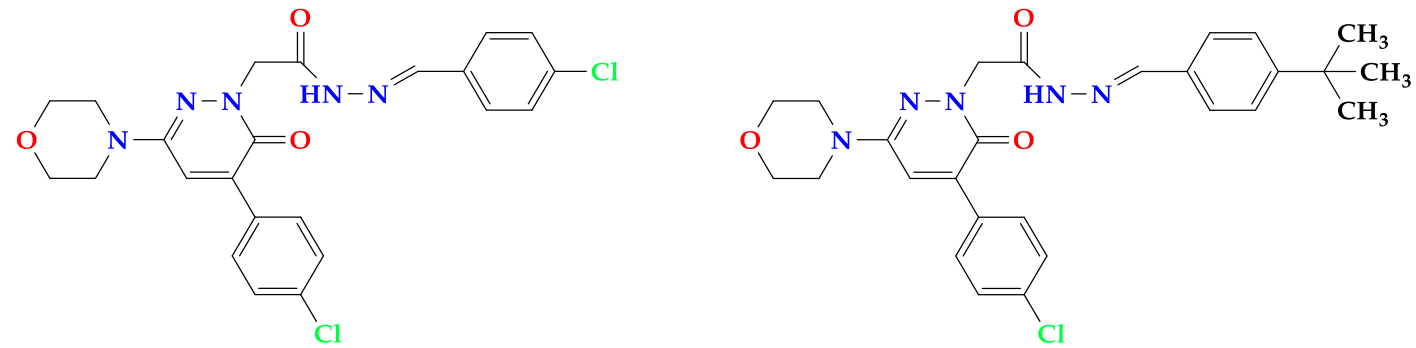

Figure 2. Structure of $N$-benzylidene acetohydrazide derivatives.

Nagle et al. synthesized the new pyridazinone derivative compounds containing the thymol structure and evaluated the antibacterial activity against $E$. coli and $S$. aureus and antifungal activity against $A$. niger and P. marneffei of these compounds and thymol by agar well diffusion method. They reported that all compounds showed bactericidal and fungicidal activity compared with ciprofloxacin and fluconazole. In this study, molecular modelling studies of synthesized compounds against glucosamine-6-phosphate synthase and $A$. niger phytase enzymes have also been made and it has been reported that compounds show high binding affinity to receptors [11] (Figure 3).

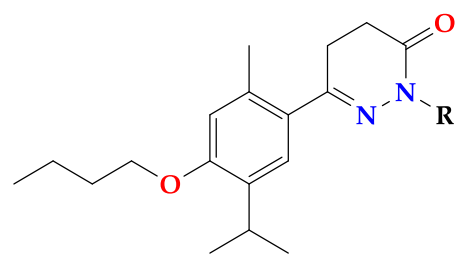

Figure 3. Structure of 3(2H)-pyridazinone bearing thymol.

Based on the above literatures, the synthesis of new $3(2 \mathrm{H})$-pyridazinone derivative compounds was carried out and the antibacterial-antifungal activities of these compounds were investigated. In the series of compounds prepared using different benzaldehyde derivatives, the contribution of different substituents on the phenyl ring to activity was investigated and it was aimed to find the precursor molecule for activity. For evaluation of antimicrobial activity, the minimum inhibitor concentration (MIC) values of the compounds were determined against standard ampicillin, gentamicin, ofloxacin, rifampicin, ampicillin-sulbactam, amoxicillin-clavulonic acid, fluconazole and amphotericin B. Binding interactions of these compounds in $C$. albicans CYP51 (CACYP51) were predicted through molecular docking using a number of free software. 


\section{RESULTS AND DISCUSSION}

\subsection{Chemistry}

6-(Substitutedphenyl)-3(2H)-pyridazinone-2-acetyl-2-(substitutedbenzal)hydrazine $\left(\mathbf{D}_{1 \mathrm{a}}-\mathbf{D}_{1 \mathrm{~d}}, \mathbf{D}_{2 \mathrm{a}}-\mathbf{D}_{2 \mathrm{~d}}\right)$ derivatives were synthesized according to Figure 4. Synthesis of the compounds were initiated by obtaining compound $\mathbf{A}_{\mathbf{1}}, \mathbf{A}_{\mathbf{2}}$ with a very useful and easy-to-use method which Schmidt and Druey developed in 1954 for synthesis of pyridazinone compounds [15]. The reaction is based on the formation of $3(2 H)$-pyridazinone derivatives by condensation of 1,2-dicarbonyl compound with monosubstituted or unsubstituted hydrazine and the carboxyl derivative containing active methylene group. Dicarbonyl compounds including 1,2diketones, a-ketoacids or glyoxal and esters, malonic acid, acetoacetic acid, cyanoacetic acid, benzoylacetic acid or hippuric acid esters are used as a-methylene reactive group [16]. In this study, glyoxalic acide was used as 1,2-dicarbonyl compound. Glyoxalic acid and acetophenone derivatives were heated with hydrazine hydrate in acidic medium to give $3(2 H)$-pyridazinone derivatives $\left(\mathbf{A}_{\mathbf{1}}, \mathbf{A}_{\mathbf{2}}\right)$. Ethyl 6-substituted-3(2H)pyridazinone-2-ylacetate derivatives $\left(\mathbf{B}_{\mathbf{1}}, \mathbf{B}\right)$ were obtained by the reaction of $\mathbf{A}_{\mathbf{1}}, \mathbf{A}_{\mathbf{2}}$ with ethyl bromoacetate in the presence of $\mathrm{K}_{2} \mathrm{CO}_{3}$ in acetone [17]. Then, 6-substituted-3(2H)-pyridazinone-2-ylacetohydrazide derivatives $\left(\mathbf{C}_{1}, \mathbf{C}_{2}\right)$ were synthesized by the condensation reaction of $\mathbf{B}_{1}, \mathbf{B}_{2}$ with hydrazine hydrate [17]. Ultimately, the title compounds bearing benzalhydrazone structure were obtained by the reaction of $\mathrm{C}_{1}, \mathrm{C}_{2}$ with substituted/nonsubstituted benzaldehydes. All of the title compounds were reported for the first time in this study. The physical and spectral properties of the starting compounds were in accordance with the literature [18]. Their chemical structures were confirmed by IR, ${ }^{1} \mathrm{H}-\mathrm{NMR}$ and mass spectral data. Synthesized pathway of $\mathbf{D}_{1 \mathrm{a}}-\mathbf{D}_{1 \mathrm{~d}}, \mathbf{D}_{\mathbf{2 a}}-\mathbf{D}_{2 \mathrm{~d}}$ have been given in Figure 4 . The melting point, yield, molecular formula and spectral data of all compounds are reported in Table 1 and Table 2.
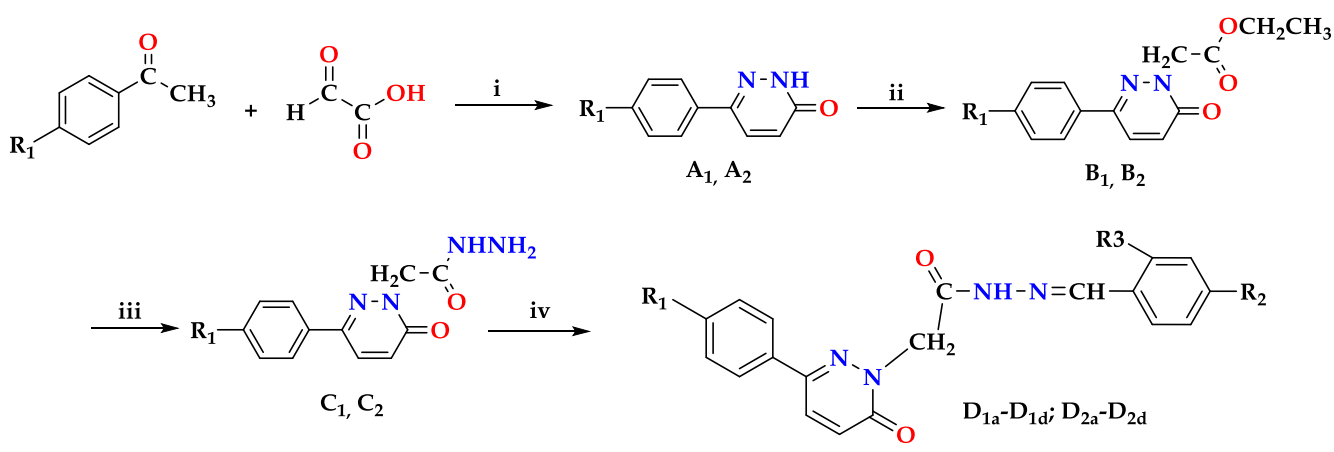

\footnotetext{
(i) reflux in oil bath (6h), $\mathrm{NH}_{4} \mathrm{OH}(25 \%), \mathrm{H}_{2} \mathrm{NNH}_{2}$; (ii) $\mathrm{BrCH}_{2} \mathrm{COOCH}_{2} \mathrm{CH}_{3}, \mathrm{~K}_{2} \mathrm{CO}_{3}$, aceton, reflux (overnight); (iii) $\mathrm{H}_{2} \mathrm{NNH}_{2} \cdot \mathrm{H}_{2} \mathrm{O}, \mathrm{MeOH}$, stirred in rt; (iv) appropriate benzaldehyde, ethanol, reflux $(6 \mathrm{~h})$

$\mathbf{R}_{1}$ : chloro, bromo ; $\mathbf{R}_{2}$ : triflouromethyl, chloro,benzyloxy, isopropyl; $\mathbf{R}_{3}$ : chloro,hydrogen
}

Figure 4. Synthesis of 6-Substituted-3(2H)-pyridazinone-2-acetyl-2-(substituted benzal)hydrazine $\mathbf{D}_{1 \mathrm{a}}-\mathbf{D}_{1 \mathrm{~d}}$ $D_{2 \mathrm{a}}-\mathrm{D}_{2 \mathrm{~d}}$ derivatives.

\subsection{Antimicrobial activity}

Standard strains of E. coli ATCC 25922, E. coli ATCC 35218, P. aeruginosa ATCC 27853, S. aureus ATCC 29213, E. faecalis ATCC 29212, C. albicans ATCC 10231 and C. krusei ATCC 6258 and clinical isolates of these microorganisms that are known to be resistant to various antimicrobial agents were included in the study. Strains were provided from Gazi University Faculty of Medicine Department of Medical Microbiology. Standard powders of ampicillin, gentamicin, ofloxacin, rifampicin, ampicillin-sulbactam, amoxicillinclavulonic acid, fluconazole and amphotericin B were obtained from the manufacturers. 
Table 1. The physical data, yield and molecular formula of 6-Substituted-3(2H)-pyridazinone-2-acetyl-2(substituted benzal)hydrazine $\mathbf{D}_{1 \mathrm{a}}-\mathbf{D}_{1 \mathrm{~d}}, \mathbf{D}_{2 \mathrm{a}}-\mathbf{D}_{2 \mathrm{~d}}$ derivatives.

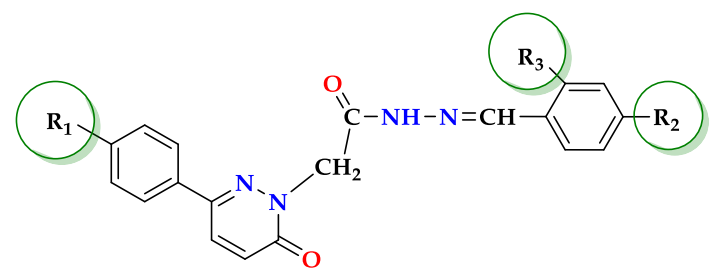

\begin{tabular}{|c|c|c|c|c|c|c|}
\hline Com. & $\mathbf{R}_{\mathbf{1}}$ & $\mathbf{R}_{\mathbf{2}}$ & $-\mathbf{R}_{3}$ & $\begin{array}{l}\mathrm{Mp} \\
\left({ }^{\circ} \mathrm{C}\right)\end{array}$ & $\begin{array}{c}\text { Yield } \\
(\%)\end{array}$ & Molecular Formula (MW) \\
\hline $\mathrm{D}_{1 \mathrm{a}}$ & $-\mathrm{Cl}$ & $-\mathrm{CF}_{3}$ & $-\mathrm{H}$ & 261 & 53 & $\begin{array}{c}\mathrm{C}_{20} \mathrm{H}_{14} \mathrm{ClF}_{3} \mathrm{~N}_{4} \mathrm{O}_{2} \\
\text { (Calc.: 435.0836; Found: 435.0837) }\end{array}$ \\
\hline $\mathrm{D}_{1 \mathrm{~b}}$ & $-\mathrm{Cl}$ & $-\mathrm{Cl}$ & $-\mathrm{Cl}$ & 266 & 54 & $\begin{array}{c}\mathrm{C}_{19} \mathrm{H}_{13} \mathrm{Cl}_{3} \mathrm{~N}_{4} \mathrm{O}_{2} \\
\text { (Calc.: 435.0182; Found: 435.0176) }\end{array}$ \\
\hline $\mathbf{D}_{1 \mathrm{c}}$ & $-\mathrm{Cl}$ & $-\mathrm{CH}\left(\mathrm{CH}_{3}\right)_{2}$ & $-\mathrm{H}$ & 186 & 88 & $\begin{array}{c}\mathrm{C}_{22} \mathrm{H}_{21} \mathrm{ClN}_{4} \mathrm{O}_{2} \\
\text { (Calc.: 409.1431; Found: 409.1450) }\end{array}$ \\
\hline $\mathrm{D}_{1 \mathrm{~d}}$ & $-\mathrm{Cl}$ & & $-\mathrm{H}$ & 236 & 63 & $\begin{array}{l}\mathrm{C}_{26} \mathrm{H}_{21} \mathrm{ClN}_{4} \mathrm{O}_{3} \\
\text { (Calc.: 473.1380; Found: 473.1384) }\end{array}$ \\
\hline $\mathrm{D}_{2 \mathrm{a}}$ & $-\mathrm{Br}$ & $-\mathrm{CF}_{3}$ & $-\mathrm{H}$ & 265 & 78 & $\begin{array}{c}\mathrm{C}_{20} \mathrm{H}_{14} \mathrm{BrF}_{3} \mathrm{~N}_{4} \mathrm{O}_{2} \\
\text { (Calc.: 479.0330; Found: 479.0332) }\end{array}$ \\
\hline $\mathrm{D}_{2 \mathrm{~b}}$ & $-\mathrm{Br}$ & $-\mathrm{Cl}$ & $-\mathrm{Cl}$ & 268 & 62 & $\begin{array}{c}\mathrm{C}_{19} \mathrm{H}_{13} \mathrm{BrCl}_{2} \mathrm{~N}_{4} \mathrm{O}_{2} \\
\text { (Calc.: 478.9677; Found: 478.9697) }\end{array}$ \\
\hline $\mathbf{D}_{2 \mathrm{c}}$ & $-\mathrm{Br}$ & $-\mathrm{CH}\left(\mathrm{CH}_{3}\right)_{2}$ & $-\mathrm{H}$ & 181 & 83 & $\begin{array}{c}\mathrm{C}_{22} \mathrm{H}_{21} \mathrm{BrN}_{4} \mathrm{O}_{2} \\
\text { (Calc.: 453.0926; Found: 453.0920) }\end{array}$ \\
\hline $\mathrm{D}_{2 \mathrm{~d}}$ & $-\mathrm{Br}$ & & $-\mathrm{H}$ & 234 & 68 & $\begin{array}{c}\qquad \mathrm{C}_{26} \mathrm{H}_{21} \mathrm{BrN}_{4} \mathrm{O}_{3} \\
\text { (Calc.: 517.0875; Found: 517.0889) }\end{array}$ \\
\hline
\end{tabular}

The MIC values of $\mathbf{D}_{1 \mathrm{a}}-\mathbf{D}_{1 \mathrm{~d}}, \mathbf{D}_{\mathbf{2 a}}-\mathbf{D}_{\mathbf{2 d}}$ were determined against standard ATCC type cultures of Eschericia coli, Pseudomonas aeruginosa, Staphylococcus aureus, Enterococcus faecalis, Candida albicans and Candida krusei (Table 3). In general, the compounds showed more potent against fungus than bacterias. Generally, compounds with chloride were more active than those with bromide as $R_{1}$ substituent. However, $\mathbf{D}_{2 \mathrm{a}}$ stood out as the most active compound in the series with lower MIC values than those of fluconazole against Candida krusei. The derivatives carrying the aromatic ring as the substituent in the hydrazide group in chlorinated compounds exhibited higher activity while the compound containing the trifluoromethyl substituent $\left(\mathbf{D}_{1 \mathrm{a}}\right)$ showed low activity. In contrast, aromatic substituents in brominated compounds caused a reduction in activity, while trifluoromethyl containing compound $\mathbf{D}_{2 a}$ was found to be the most active compound. The results of molecular modelling confirmed this situation.

\subsection{Molecular modelling}

Molecular modelling studies have been carried out to predict the mechanism of action of antifungal activity because of the moderate antifungal activity of the compounds. Molecular modelling studies have screened whether compounds inhibit the CYP51 enzyme of Candida albicans [19]. The model includes VT1161, a tight binder of CYP51 in the catalytic site. Because of its structural similarity to the compounds that we synthesized, the enzyme to which this ligand is bound was selected (5TZ1). 
A redocking study was performed in order to evaluate how close the software/algorithms used in this study predicted the binding mode of VT116 regarding its original conformation in CACYP51 catalytic site. The results confirmed that the methods worked well (Table 4).

Table 2. Spectral data of 6-substituted-3(2H)-pyridazinone-2-acetyl-2-(substituted benzal)hydrazine $\mathbf{D}_{1 \mathbf{a}}$ $\mathbf{D}_{1 \mathrm{~d}}, \mathbf{D}_{2 \mathrm{a}}-\mathbf{D}_{2 \mathrm{~d}}$ derivatives. (see Table 1 for structural formula).

\begin{tabular}{|c|c|c|c|c|c|c|}
\hline \multirow[b]{2}{*}{ Comp } & \multicolumn{4}{|c|}{ IR (KBr) $\mathbf{c m}^{-1}$} & \multirow[b]{2}{*}{$\begin{array}{c}\left.{ }^{1} \mathrm{H} \text { NMR( DMSO- } d_{6}\right) \text { ppm } \\
(\delta)\end{array}$} & \multirow[b]{2}{*}{ 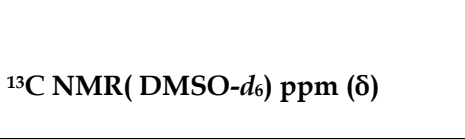 } \\
\hline & $\mathrm{C}=\mathrm{O}$ & $\begin{array}{l}\text { Aromatic C- } \\
\text { H Aliphatic } \\
\text { C-H }\end{array}$ & $\mathrm{C}=\mathrm{N}$ & $\mathrm{N}-\mathrm{H}$ & & \\
\hline $\mathbf{D}_{1 \mathrm{a}}$ & 1652 & $3139 / 2965$ & 1591 & 3341 & $\begin{array}{l}4.94\left(-\mathrm{N}-\mathrm{CH}_{2}-\mathrm{C}=\mathrm{O} ; 2 \mathrm{H} ; \mathrm{s} ;\right. \\
\% 25), \quad 5.35 \quad\left(-\mathrm{N}-\mathrm{CH}_{2}-\mathrm{C}=\mathrm{O} ;\right. \\
2 \mathrm{H} \text { s; } \% 75), \quad 7.13 \\
\text { (pyridazinone } \mathrm{H}^{5}, 1 \mathrm{H} ; \mathrm{d} ; \\
J=9,78 \quad \mathrm{~Hz}), \quad 7.56 \\
\text { (pyridazinone } \mathrm{H}^{4}, 1 \mathrm{H} ; \mathrm{d} ; \\
J=8,64 \quad \mathrm{~Hz}), \quad 7.59-8.15 \\
\text { (phenyl protons; } 8 \mathrm{H} ; \mathrm{m}), \\
8.31 \text { (-N=CH- ; } 1 \mathrm{H} ; \mathrm{s}) \text { and } \\
11.97 \text { (NH-N 1H; s). }\end{array}$ & 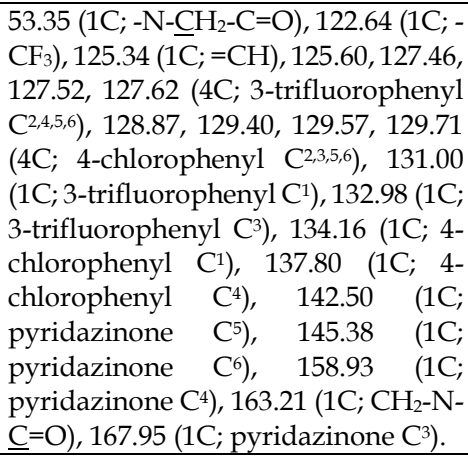 \\
\hline $\mathrm{D}_{1 \mathrm{~b}}$ & 1677 & 3085 / 2961 & 1593 & 3323 & $\begin{array}{l}4.92\left(-\mathrm{N}-\mathrm{CH}_{2}-\mathrm{C}=\mathrm{O} ; 2 \mathrm{H} ; \mathrm{s} ;\right. \\
\% 25), 5.33 \quad\left(-\mathrm{N}-\mathrm{CH}_{2}-\mathrm{C}=\mathrm{O} ;\right. \\
2 \mathrm{H} ; \mathrm{s} ; \quad \% 75), \quad 7.13 \\
\text { (pyridazinone } \mathrm{H}^{5}, 1 \mathrm{H} ; \mathrm{d} ; \\
\mathrm{J}=9.78 \quad \mathrm{~Hz}), \quad 7.50 \\
\text { (pyridazinone } \mathrm{H}^{4}, 1 \mathrm{H} ; \mathrm{d} ; \\
J=8.43 \quad \mathrm{~Hz}), \quad 7.55-8.15 \\
\text { (phenyl protons; } 7 \mathrm{H} ; \mathrm{m}), \\
8.37 \text { (-N=CH- ; } 1 \mathrm{H} ; \mathrm{s}) \text { and } \\
12.01 \text { (NH-N 1H; s). }\end{array}$ & 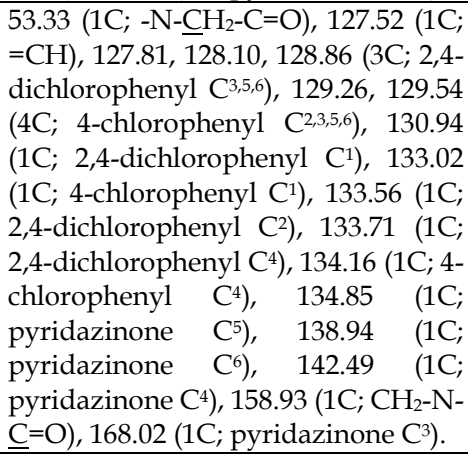 \\
\hline $\mathbf{D}_{1 \mathrm{c}}$ & 1679 & 3056 / 2961 & 1590 & 3230 & $\begin{array}{l}1.22\left(-\mathrm{CH}_{3}, 6 \mathrm{H} ; \mathrm{d} ; J=6.91\right. \\
\mathrm{Hz}), 2.92 \quad(-\mathrm{CH}, 1 \mathrm{H} ; \mathrm{m} ; \\
\mathrm{J}=6.91 \mathrm{~Hz}), 4.90\left(-\mathrm{N}-\mathrm{CH}_{2-}\right. \\
\mathrm{C}=\mathrm{O} ; 2 \mathrm{H} ; \mathrm{s} ; \% 25), 5.30(-\mathrm{N}- \\
\left.\mathrm{CH}_{2}-\mathrm{C}=\mathrm{O} ; 2 \mathrm{H} ; \mathrm{s} ; \% 75\right), 7.12 \\
\text { (pyridazinone } \mathrm{H}^{5}, 1 \mathrm{H} ; \mathrm{d} ; \\
J=9.78 \quad \mathrm{~Hz}), \quad 7.32 \\
\text { (pyridazinone } \mathrm{H}^{4}, 1 \mathrm{H} ; \mathrm{d} ; \\
J=8.19 \quad \mathrm{~Hz}), \quad 7.55-8.19 \\
\text { (phenyl protons; } 8 \mathrm{H} ; \mathrm{m}), \\
8.31(-\mathrm{N}=\mathrm{CH}-; 1 \mathrm{H} ; \mathrm{s}) \text { and } \\
11.71(\mathrm{NH}-\mathrm{N} 1 \mathrm{H} ; \mathrm{s}) .\end{array}$ & 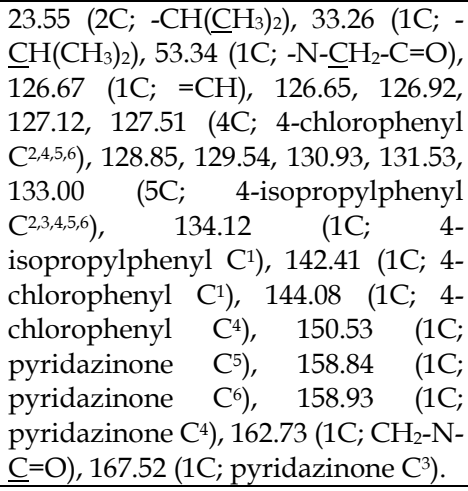 \\
\hline$D_{1 d}$ & 1677 & 3039 / 2910 & 1596 & 3180 & 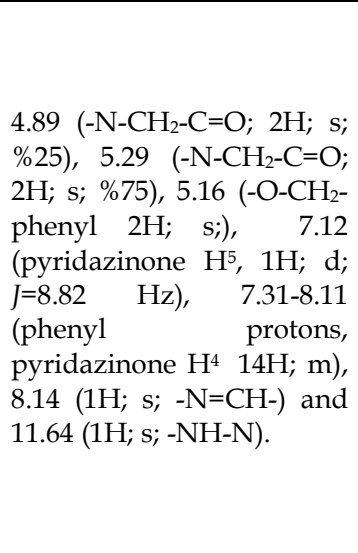 & 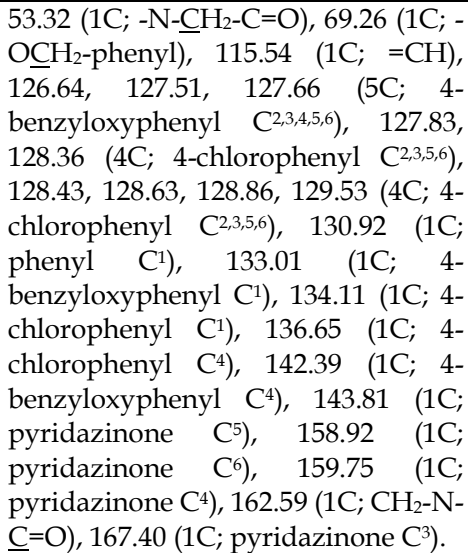 \\
\hline
\end{tabular}




\begin{tabular}{|c|c|c|c|c|c|}
\hline \multirow[b]{2}{*}{ Comp } & \multicolumn{4}{|c|}{ IR (KBr) $\mathrm{cm}^{-1}$} & \multirow[b]{2}{*}{$\underset{(\delta)}{\left.{ }^{1} \mathrm{H} \text { NMR( DMSO- } d_{6}\right) \mathrm{ppm}}$} \\
\hline & $\mathrm{C}=\mathrm{O}$ & $\begin{array}{l}\text { Aromatic C- } \\
\text { H Aliphatic } \\
\text { C-H }\end{array}$ & $\mathrm{C}=\mathrm{N}$ & $\mathrm{N}-\mathrm{H}$ & \\
\hline $\mathbf{D}_{2 \mathrm{a}}$ & 1651 & 3069 / 2958 & 1589 & 3280 & $\begin{array}{l}4.94\left(-\mathrm{N}-\mathrm{CH}_{2}-\mathrm{C}=\mathrm{O} ; 2 \mathrm{H} ; \mathrm{s} ;\right. \\
\% 25), \quad 5.35 \quad\left(-\mathrm{N}-\mathrm{CH}_{2}-\mathrm{C}=\mathrm{O} ;\right. \\
2 \mathrm{H} ; \quad \mathrm{s} ; \quad \% 75), \quad 7.14 \\
\text { (pyridazinone } \mathrm{H}^{5}, 1 \mathrm{H} ; \mathrm{d} ; \\
J=9.72 \quad \mathrm{~Hz}), \quad 7.69-8.14 \\
\text { (phenyl } \quad \text { protons, } \\
\left.\text { pyridazinone } \mathrm{H}^{4} ; 9 \mathrm{H} ; \mathrm{m}\right), \\
8.31(-\mathrm{N}=\mathrm{CH}-; \mathrm{H} ; \mathrm{s}) \text { and } \\
11.96(\mathrm{NH}-\mathrm{N} 1 \mathrm{H} ; \mathrm{s}) .\end{array}$ \\
\hline
\end{tabular}

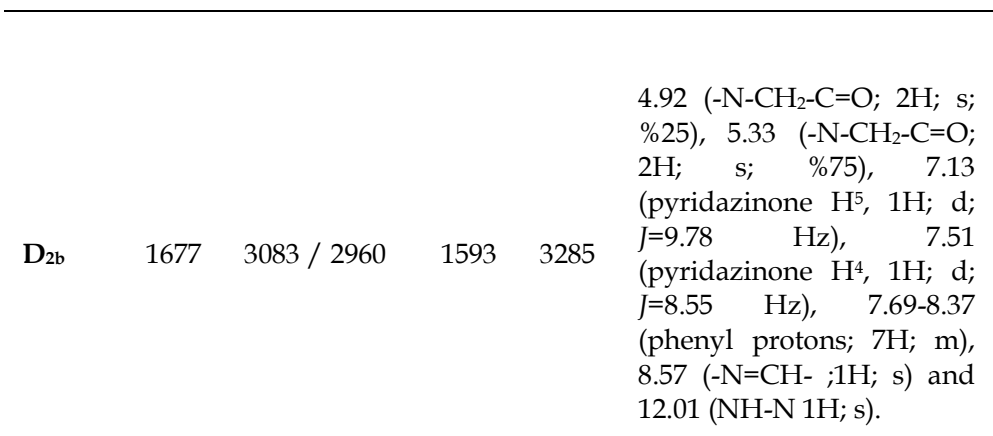

\begin{tabular}{|c|c|c|c|c|c|}
\hline & & & & & $\begin{array}{l}1.23\left(-\mathrm{CH}_{3}, 6 \mathrm{H} ; \mathrm{d} ; \mathrm{J}=6,90\right. \\
\mathrm{Hz}), 2.92(-\mathrm{CH}, 1 \mathrm{H} ; \mathrm{m} ; \mathrm{J}=6.9 \\
\mathrm{Hz}), \quad 4.90 \quad\left(-\mathrm{N}^{-} \mathrm{CH}_{2}-\mathrm{C}=\mathrm{O} \text {; }\right. \\
2 \mathrm{H} ; \mathrm{s} ; \% 25), \quad 5.29\left(-\mathrm{N}-\mathrm{CH}_{2}-\right. \\
\mathrm{C}=\mathrm{O} ; \quad 2 \mathrm{H} ; \quad \mathrm{s} ; \% 75), \quad 7.12 \\
\text { (pyridazinone } \mathrm{H}^{5}, 1 \mathrm{H} ; \mathrm{d} ;\end{array}$ \\
\hline$D_{2 c}$ & 1677 & 3052 / 2959 & 1591 & 3260 & $\begin{array}{l}J=9.75 \quad \mathrm{~Hz}), \quad 7.32 \\
\text { (pyridazinone } \mathrm{H}^{4}, 1 \mathrm{H} ; \mathrm{d} ; \\
J=8.10 \mathrm{~Hz}), \quad 7.71-8.14 \\
\text { (phenyl protons; 8H; m), } \\
8.19(-\mathrm{N}=\mathrm{CH}-\text {; } 1 \mathrm{H} ; \mathrm{s}) \text { and } \\
11.72(\mathrm{NH}-\mathrm{N} 1 \mathrm{H} ; \mathrm{s}) .\end{array}$ \\
\hline
\end{tabular}

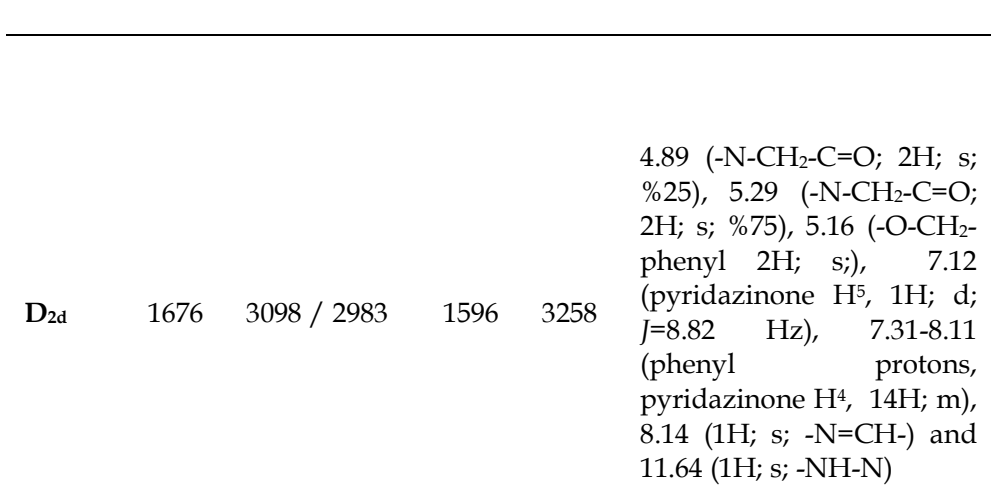
$53.36\left(1 \mathrm{C} ;-\mathrm{N}-\mathrm{CH}_{2}-\mathrm{C}=\mathrm{O}\right), 122.64(1 \mathrm{C} ;-$
$\left.\mathrm{CF}_{3}\right), 125.59(1 \mathrm{C} ;=\mathrm{CH}), 125.60,127.46$, 127.63, 127.77 (4C; 3-trifluorophenyl $\left.C^{2,4,5,6}\right), 129.56,129.72,130.95,131.09$ (4C; 4-bromophenyl $\left.C^{2,3,5,6}\right), 131.79$ (1C; 3-trifluorophenyl $\left.C^{1}\right), 133.34$ (1C; 3-trifluorophenyl C3), 134.16 (1C; 4bromophenyl $\left.\mathrm{C}^{1}\right), 137.79$ (1C; 4bromophenyl $\left.\mathrm{C}^{4}\right), \quad 142.40 \quad(1 \mathrm{C}$; pyridazinone $\left.C^{5}\right), \quad 145.38 \quad(1 C$; pyridazinone $\left.\mathrm{C}^{6}\right), 158.95 \quad(1 \mathrm{C}$; pyridazinone $\left.\mathrm{C}^{4}\right), 163.20\left(1 \mathrm{C} ; \mathrm{CH}_{2}-\mathrm{N}-\right.$ $\mathrm{C}=\mathrm{O}), 167.95$ (1C; pyridazinone $\mathrm{C}^{3}$ ).

53.31 (1C; $\left.-\mathrm{N}-\mathrm{CH}_{2}-\mathrm{C}=\mathrm{O}\right), 122.88$ (1C; $=\mathrm{CH}), \quad 127.76,128.13 \quad$ (3C; $2,4-$ dichlorophenyl $\left.\mathrm{C}^{3,5,6}\right), 129.27,129.55$, 130.25, 130.91 (4C; 4-bromophenyl

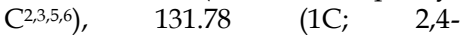
dichlorophenyl $\left.\mathrm{C}^{1}\right), 133.36(1 \mathrm{C}$; 4bromophenyl $\left.\mathrm{C}^{1}\right), 133.62$ (1C; 2,4dichlorophenyl $C^{2}$ ), 134.96 (1C; 2,4dichlorophenyl C4), 139.10 (1C; 4bromophenyl $\left.\mathrm{C}^{4}\right), \quad 142.09 \quad(1 \mathrm{C}$; pyridazinone $\left.\mathrm{C}^{5}\right), \quad 142.59 \quad(1 \mathrm{C}$; pyridazinone $\left.\mathrm{C}^{6}\right), \quad 158.93 \quad(1 \mathrm{C}$; pyridazinone $\left.\mathrm{C}^{4}\right), 163.12\left(1 \mathrm{C} ; \mathrm{CH}_{2}-\mathrm{N}\right.$ $\underline{\mathrm{C}}=\mathrm{O}), 167.85$ (1C; pyridazinone $\left.\mathrm{C}^{3}\right)$.

$23.55\left(2 \mathrm{C} ;-\mathrm{CH}\left(\mathrm{CH}_{3}\right)_{2}\right), 33.27(1 \mathrm{C}$; $\left.\underline{\mathrm{CH}}\left(\mathrm{CH}_{3}\right)_{2}\right), 53.36\left(1 \mathrm{C} ;-\mathrm{N}-\mathrm{C}_{2}-\mathrm{C}=\mathrm{O}\right)$, $126.87(1 \mathrm{C} ;=\mathrm{CH}), 126.68,126.93$, 127.13, 127.76 (4C; 4-bromophenyl $\left.\mathrm{C}^{2,4,5,6)}\right)$ 131.54, 131.78, 133.36, 142.49, $142.60 \quad$ (5C; 4-isopropylphenyl $\mathrm{C}^{2,3,4,5,6)}$, $144.09 \quad(1 \mathrm{C} ; \quad 4-$ isopropylphenyl $\left.C^{1}\right), 147.01$ (1C; 4bromophenyl $\left.\mathrm{C}^{1}\right), 150.54$ (1C; 4bromophenyl $\left.\mathrm{C}^{4}\right), \quad 150.67 \quad(1 \mathrm{C}$; pyridazinone $\left.\mathrm{C}^{5}\right), \quad 158.94 \quad(1 \mathrm{C}$; pyridazinone $\left.\mathrm{C}^{6}\right), \quad 162.74 \quad(1 \mathrm{C}$; pyridazinone $\left.\mathrm{C}^{4}\right), 163.34\left(1 \mathrm{C} ; \mathrm{CH}_{2}-\mathrm{N}-\right.$ $\underline{\mathrm{C}}=\mathrm{O}), 167.51$ (1C; pyridazinone $\left.\mathrm{C}^{3}\right)$. $53.41\left(1 \mathrm{C} ;-\mathrm{N}-\underline{C H}_{2}-\mathrm{C}=\mathrm{O}\right), 69.33(1 \mathrm{C} ;-$ $\mathrm{OCH}_{2}$-phenyl), $115.12(1 \mathrm{C} ;=\mathrm{CH})$, $126.71,126.80,127.72,127.81,127.89$ (5C; 4-benzyloxyphenyl $\left.\mathrm{C}^{2,3,4,5,6}\right)$, $128.43,128.50,128.70,129.60$ (4C; $4-$ bromophenyl $\mathrm{C}^{2,3,5,6)}$, 130.92, 131.83, 133.43, 136.72 (4C; 4-bromophenyl $\left.\mathrm{C}^{2,3,3,6}\right), 142.52$ (1C; phenyl $\left.\mathrm{C}^{1}\right), 142.65$ (1C; 4-benzyloxyphenyl $\left.C^{1}\right), 143.90$ (1C; 4-bromophenyl $\left.\mathrm{C}^{1}\right), 146.96(1 \mathrm{C}$; 4-bromophenyl C4), 158.92 (1C; 4benzyloxyphenyl $\left.\mathrm{C}^{4}\right), 159.01 \quad(1 \mathrm{C}$; pyridazinone $\left.\mathrm{C}^{5}\right), \quad 159.82 \quad(1 \mathrm{C}$; pyridazinone $\left.\mathrm{C}^{6}\right), \quad 159.94 \quad(1 \mathrm{C}$; pyridazinone $\left.\mathrm{C}^{4}\right), 162.67\left(1 \mathrm{C} ; \mathrm{CH}_{2}-\mathrm{N}-\right.$ $\underline{\mathrm{C}}=\mathrm{O}), 167.47$ (1C; pyridazinone $\left.\mathrm{C}^{3}\right)$.

Docking studies showed that $\mathbf{D}_{2 \mathrm{a}}$ bound to the catalytic site of CACYP51 with high affinity (Table 5) and in a similar way determined for azole antifungals in crystallography studies (Figure 5). According to the binding modes obtained from several software and algorithms the 4-trifluoromethylbenzen ring placed close to the heme and $\mathrm{Fe}^{+2}$, the 4-bromobenzen fit in the cleft surrounded by His377 making pi-pi stacking and the tail groups interacted with residues that form the active site gorge, e.g. Gly303, Ile131, Thr122, Thr122, Leu121, 
Tyr118, Leu376, Phe233 (Figure 5, Figure 6) [20]. Molecular modelling studies were also conducted for the fluconazole compound, which is used as a reference compound in in vitro studies. Although the binding profiles of the fluconazole compound are lower than the $\mathbf{D}_{2 \mathrm{a}}$ compound, the fluconazole compound shows higher efficacy against Candida albicans. This suggests that fluconazole has activity over a different pathway or that the compound we synthesized may not have reached the enzyme site at sufficient concentration in in vitro cell studies.

Table 3. In vitro antibacterial and antifungal activity of 6-Substituted-3(2H)-pyridazinone-2-acetyl-2(substituted benzal)hydrazone derivatives $\left(\mathbf{D}_{1 \mathrm{a}}-\mathbf{D}_{1 \mathrm{~d}}, \mathbf{D}_{\mathbf{2} \mathrm{a}}-\mathbf{D}_{2 \mathrm{~d}}\right)$.

\begin{tabular}{|c|c|c|c|c|c|c|c|c|c|c|c|}
\hline Compound & A & B & $\mathrm{C}$ & D & $\mathbf{E}$ & $\mathbf{F}$ & G & $\mathbf{H}$ & I & $\mathbf{J}$ & $\mathbf{K}$ \\
\hline$D_{1 a}$ & 16 & 16 & 16 & 32 & 32 & 16 & 64 & 64 & 64 & 32 & 32 \\
\hline $\mathrm{D}_{1 \mathrm{~b}}$ & 16 & 16 & 16 & 32 & 32 & 16 & 16 & 16 & 16 & 8 & 8 \\
\hline$D_{1 c}$ & 16 & 16 & 16 & 32 & 32 & 16 & 16 & 16 & 16 & 8 & 8 \\
\hline $\mathrm{D}_{1 \mathrm{~d}}$ & 16 & 16 & 16 & 32 & 32 & 16 & 16 & 16 & 16 & 8 & 8 \\
\hline$D_{2 a}$ & 16 & 16 & 16 & 32 & 16 & 16 & 8 & 32 & 16 & 8 & 8 \\
\hline $\mathrm{D}_{2 \mathrm{~b}}$ & 64 & 64 & 64 & 32 & 64 & 16 & 64 & 64 & 64 & 32 & 32 \\
\hline$D_{2 c}$ & 64 & 64 & 64 & 32 & 16 & 16 & 64 & 64 & 64 & 32 & 32 \\
\hline $\mathrm{D}_{2 \mathrm{~d}}$ & 64 & 64 & 64 & 32 & 32 & 64 & 64 & 64 & 64 & 32 & 32 \\
\hline Ampicillin & 2 & - & $>512$ & - & - & 0.5 & - & 0.5 & 0.5 & - & - \\
\hline Gentamicin & 0.25 & - & 128 & 1 & 64 & 0.5 & 64 & 8 & 8 & - & - \\
\hline Ofloxacin & 0.015 & - & 128 & 1 & 2 & 0.25 & 0.5 & 1 & 4 & - & - \\
\hline Rifampicin & 16 & - & 128 & 32 & 32 & 0.004 & 2 & 0.5 & 4 & - & - \\
\hline Ampicillin-Sulbactam & - & 16 & - & - & - & - & - & - & - & - & - \\
\hline Amoxicillin-Clavulonic acid & - & 16 & - & - & - & - & - & - & - & - & - \\
\hline Fluconazole & - & - & - & - & - & - & - & - & - & 0.0625 & 32 \\
\hline Amphotericin B & - & - & - & - & - & - & - & - & - & $<0.03$ & 0.5 \\
\hline
\end{tabular}

A: Eschericia coli ATCC 25922, B: E. coli ATCC 35218, C: E. coli isolat (ESBL), D: Pseudomonas aeruginosa ATCC 27853, E: P. aeruginosa isolat (Resistant to gentamycin), F: Staphylococcus aureus ATCC 29213, G: S. aureus isolat (Resistant to Methicillin), H: Enterococcus faecalis ATCC 29212, I: E. faecalis isolat (Resistant to Vancomycin), J: Candida albicans ATCC 10231, K: Candida krusei ATCC 6258.

Table 4. RMSD values ( $\AA$ ) of VT1161 docked to CACYP51 catalytic site regarding its original conformer and docking scores of VT1 for each software/algorithm.

\begin{tabular}{lcc}
\hline VT1161 & Autodock & AutoDock Vina \\
\hline RMSD $(\AA)$ & 1.37 & 1.38 \\
Docking score $^{\mathrm{a}}$ & -10.14 & -12.2 \\
\hline
\end{tabular}

a free energy of binding $(\mathrm{kcal} / \mathrm{mol})$ for AutoDock and AutoDock Vina. 
Table 5. Molecular docking binding scores and binding interactions of $\mathbf{D}_{2 \mathbf{a}}$, VT1161 and fluconazole, and within the CACYP51 active site.

\begin{tabular}{|c|c|c|c|c|c|c|c|}
\hline \multirow[t]{2}{*}{ Compound } & \multicolumn{2}{|c|}{$\begin{array}{c}\text { Estimated Free } \\
\text { Energy of Binding } \\
\text { (kcal/mol) }\end{array}$} & \multirow{2}{*}{$\begin{array}{c}\text { Estimated } \\
\text { Inhibition } \\
\text { Constant, } \\
\text { Ki, } \\
\text { Temp.= } \\
298.15 \mathrm{~K}\end{array}$} & \multirow{2}{*}{$\begin{array}{l}\text { H-bonds } \\
\text { Residue }\end{array}$} & \multirow{2}{*}{$\begin{array}{c}\text { Close } \\
\text { van der } \\
\text { Waals } \\
\text { contacts } \\
\text { Residue }\end{array}$} & $\begin{array}{l}\text { Pi-pi } \\
\text { stacking }\end{array}$ & \multirow{2}{*}{$\begin{array}{l}\text { Pi-cation } \\
\text { Residue }\end{array}$} \\
\hline & Autodock & Vina & & & & Residue & \\
\hline$D_{2 a}$ & -10.56 & -11.3 & $18.12 \mathrm{nM}$ & $\begin{array}{l}\text { Tyr132-2.66 } \\
\text { (O17)(aromatic } \\
\text { H bond) }\end{array}$ & $\begin{array}{l}\text { Gly303, } \\
\text { Ile131 } \\
\text { Thr122 } \\
\text { Thr122 } \\
\text { Leu121 } \\
\text { Tyr118 } \\
\text { Leu376 } \\
\text { Phe233 } \\
\text { His377- } \\
\text { Pro230 } \\
\text { Pro230 }\end{array}$ & His377-A & $\begin{array}{l}\text { Hem601- } \\
\text { C }\end{array}$ \\
\hline Fluconazole & -6.31 & -8.4 & $23.62 \mu \mathrm{M}$ & & $\begin{array}{l}\text { Phe126 } \\
\text { Gly307 } \\
\text { Try132 }\end{array}$ & Tyr118 & \\
\hline VT1161 & -10.14 & -12.2 & $36.91 \mathrm{nM}$ & $\begin{array}{l}\text { Met508 } \\
\text { HOH738- } \\
\text { Tyr132 }\end{array}$ & $\begin{array}{l}\text { Ser378 } \\
\text { Phe380 } \\
\text { Tyr64 } \\
\text { Phe233 } \\
\text { Leu121 } \\
\text { Ile304 } \\
\text { Gly303 } \\
\text { Tyr132 }\end{array}$ & $\begin{array}{l}\text { Hem601 } \\
\text { Phe233 }\end{array}$ & Hem601 \\
\hline
\end{tabular}

\section{CONCLUSION}

As sustenance of our research interest in developing novel pyridazinone derivative antimicrobial compounds and establishing new relationships between their structure and activity, we designed and synthesized eight new 6-substituted-3(2H)-pyridazinone derivatives and evaluated their antimicrobial activities. All compounds showed antibacterial activity at $16-64 \mu \mathrm{g} / \mathrm{ml}$ concentration and antifungal activity at $8-32 \mu \mathrm{g} / \mathrm{ml}$ concentration. We reached one hit molecules, namely $\mathbf{D}_{\mathbf{2}}$, the latter of which showed good activity against standard S. aureus isolat, C. albicans and C. krusei.

We docked $\mathbf{D}_{2 \mathrm{a}}$ to the catalytic site of the CACYP51 homology model featuring full membrane spanning anchor domain, which we previously reported, using two different software/algorithms. These findings together show that $\mathbf{D}_{2 \mathrm{a}}$ may be evaluated as developed precursor compound, could act through CYP51 inhibition.

\section{MATERIALS AND METHODS}

\subsection{Materials}

All chemicals used in this study were purchased from Aldrich, Fluka AG and E. Merck. 6-substitute$3(2 H)$-pyridazinones, ethyl 6-substitute-3(2H)-pyridazinon-2-yl acetates and 6-substitute-3(2H)-pyridazinon2-yl acetohydrazides were synthesized according to literature methods [11-13]. Analytical thin-layer chromatography (TLC) was performed on plates precoated with silica gel (Merck Kieselgel $\mathrm{F}_{254}$ plates. Melting points of the compounds were determined on Electrothermal 9200 melting points apparatus (Southent, Great Britain) and the values given are uncorrected. The IR spectra of the compounds were recorded on a Bruker Vector 22 IR spectrophotometer (Bruker Analytische Messtechnik, Karlsrure, Germany). The ${ }^{1} \mathrm{H}-\mathrm{NMR}$ and ${ }^{13} \mathrm{C}-\mathrm{NMR}$ of the compounds spectra were recorded on a Bruker Avonce $300 \mathrm{MHz}$ Ultrashield ${ }^{\mathrm{TM}} \mathrm{NMR}$ Spectrometer using tetramethylsilane as an internal standard at İnönü University and Ankara University. All 
the chemical shifts were recorded as $\delta$ (ppm). High resolution mass spectra data (HRMS) were collected in house using a Waters LCT Premier XE Mass Spectrometer (high sensitivity orthogonal acceleration time-offlight instrument) operating in ESI $(+)$ method, also coupled to an AQUITY Ultra Performance Liquid Chromatography system (Waters Corporation, Milford, MA, USA). IR spectra were obtained using a Perkin Elmer Spectrum 400 FTIR/FTNIR spectrometer equipped with a Universal ATR Sampling Accessory.

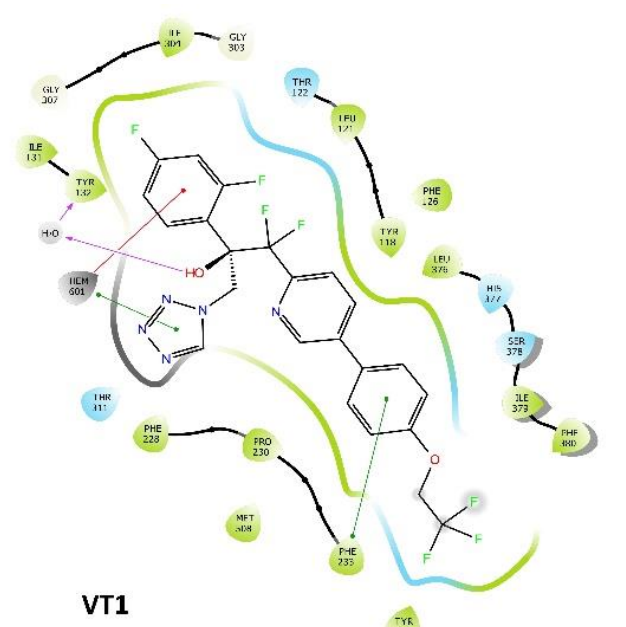

$\underset{\mathrm{rk}}{\mathrm{si}}$
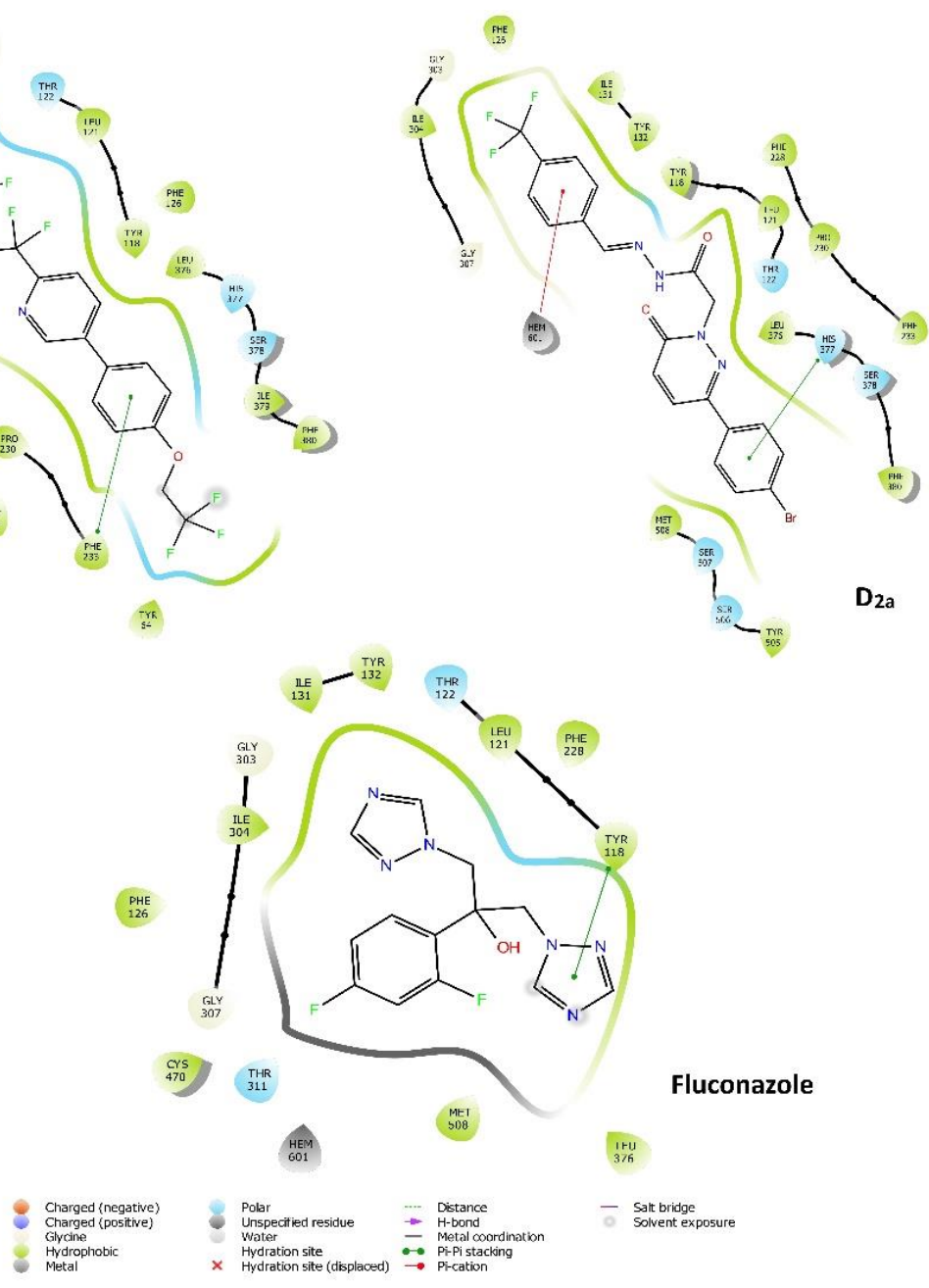

Figure 5. Superimposition of the binding modes of $\mathbf{D}_{2 \mathrm{a}}$ in CACYP51 catalytic site obtained from Autodock, 2D interaction diagram of $\mathbf{D}_{2 a}$, VT1161 and fluconazole.
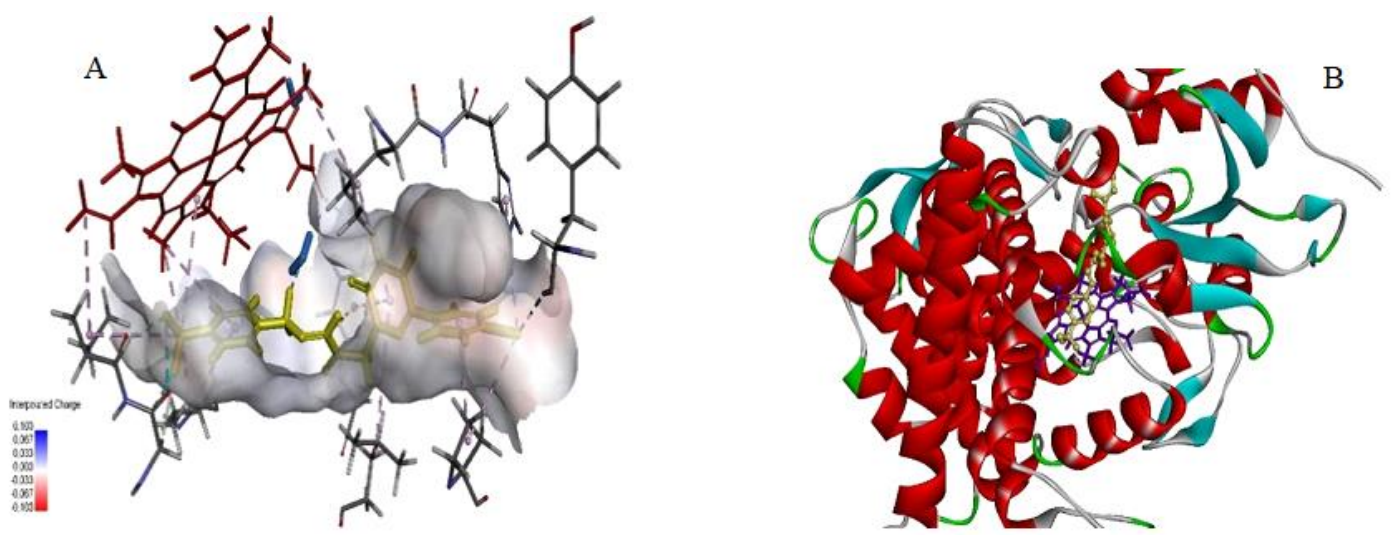

Figure 6. Compound $\mathrm{D}_{2 \mathrm{a}}$ (yellow sticks) in the binding site (molecular surface rendered) of CACYP51 (A). Compounds $\mathrm{D}_{2 \mathrm{a}}$ (yellow) is presented into the CACYP51 catalytic site (PDB ID: 5TZ1) (second fig.). Hem protein (red in first fig., purple in B) is shown as stick. For clarity, receptor residues are shown as cartoon. 


\subsection{Methods}

\subsubsection{Chemistry}

The fine chemicals and all solvents used in this study were purchased locally from E. Merck (Darmstadt, F. R. Germany) and Aldrich Chemical Co. (Steinheim, Germany).

\section{Synthesis of 6-(4-chloro/4-bromophenyl)-3(2H)-pyridazinone $A_{1}, A_{2}$}

Glyoxylic acid $(0.05 \mathrm{~mol})$ and $(0.15 \mathrm{~mol})$ 4-chloro/bromoacetophenone were heated at $100-105^{\circ} \mathrm{C}$ for 2 $\mathrm{h}$. At the end of this period, the reaction mixture was cooled to $40^{\circ} \mathrm{C}$ and then, $20 \mathrm{~mL}$ water and $5 \mathrm{~mL}$ ammonium hydroxide solution (25\%) were added to the reaction mixture until the medium $\mathrm{pH}$ became 8 . Then, reaction mixture was extracted with dichloromethane. Hydrazine hydrate (0.05 mol) was added to the separated aqueous layer and the reaction mixture was refluxed for $2 \mathrm{~h}$. After the completion of the reaction, reaction mixture was cooled to room temperature. The resulting precipitate was filtered to give compounds $\mathbf{A}_{1}, \mathbf{A}_{2}$. The measured melting points for $A_{1}$ and $A_{2}$ were in agreement with the literature $\left(A_{1}\right.$ found: $239-241^{\circ} \mathrm{C}$, $\mathrm{A}_{1}$ literature: $235-237^{\circ} \mathrm{C}$; A2: $\left.263-265^{\circ} \mathrm{C}\right)[14,21]$.

\section{Synthesis of ethyl 6-(4-chloro/4-bromophenyl)-3(2H)-pyridazinone-2-ylacetate $B_{1}, B_{2}$}

A mixture of 0.01 mol 6-(4-chloro/4-bromophenyl)-3(2H)-pyridazinone derivatives $\mathbf{A}_{1}, \mathbf{A}_{2}, 0.02$ mol (2.2252 $\mathrm{ml})$ ethyl bromoacetate, and $0.02 \mathrm{~mol}(2.7636 \mathrm{~g})$ potassium carbonate in acetone (40 ml) was refluxed overnight. After the mixture was cooled, the organic precipitat were filtered off, the solvent was evaporated, and the residue was purified by recrystallization with methanol to give the esters. The measured melting points for $B_{1}$ and $B_{2}$ were in agreement with the literature $\left(B_{1}\right.$ found: $172-174^{\circ} C, B_{1}$ literature: $171-172^{\circ} C$; $B_{2}$ found: $167-169^{\circ} \mathrm{C}$; $\mathrm{B}_{2}$ literature: $\left.164-166^{\circ} \mathrm{C}\right)[12,22,23]$.

\section{Synthesis of 6-(4-chloro/4-bromophenyl)-3(2H)-pyridazinone-2-yl acetohydrazide $C_{1}, C_{2}$}

Hydrazine hydrate $(99 \%, 3 \mathrm{ml})$ was added to the solution of 0.01 mol ethyl 6-(4-chloro/4-bromophenyl)3(2H)-pyridazinone-2-yl acetate derivatives $\mathbf{B}_{\mathbf{1}}, \mathbf{B}_{\mathbf{2}}$ in $25 \mathrm{ml}$ methanol and stirred for $3 \mathrm{~h}$ at room temperature. The precipitate obtained was filtered off, washed with water, dried, and recrystallized from ethanol. The measured melting points for $C_{1}$ and $C_{2}$ were in agreement with the literature $\left(C_{1}\right.$ found: $226-228^{\circ} C, C_{1}$ literature: $223-226^{\circ} \mathrm{C} ; \mathrm{C}_{2}$ found: $202-204^{\circ} \mathrm{C} ; \mathrm{C}_{2}$ literature: $\left.204-205^{\circ} \mathrm{C}\right)[13,24,25]$.

General procedure for synthesis of 6-(4-chloro/4-bromophenyl)-3(2H)-pyridazinone-2-acetyl-2-(substituted/ nonsubstituted benzal)hydrazonederivatives $D_{1 a}-D_{1 d}, D_{2 a}-D_{2 d}$

Mixture of 6-(4-chloro/4-bromophenyl)-3(2H)-pyridazinone-2-yl-acetohydrazide derivatives $\mathbf{C}_{\mathbf{1}}, \mathbf{C}_{2}$ $(0.01 \mathrm{~mol})$ and appropriate non substituted/substituted benzaldehyde $(0.01 \mathrm{~mol})$ were refluxed in $15 \mathrm{~mL}$ ethanol for $6 \mathrm{~h}$. Then the mixture was poured into ice-water. The precipitate formed was recrystallized from appropriate solvent.

\subsection{Antibacterial and antifungal activity}

\subsubsection{Material}

The following bacteria were used for antibacterial study: Standard strains of Escherichia coli ATCC 25922, Escherichia coli ATCC 35218, Pseudomonas aeruginosa ATCC 27853, Staphylococcus aureus ATCC 29213, Enterococcus faecalis ATCC 29212. The following yeast-like fungi were used for antifungal study; Candida albicans ATCC 10231 and Candida krusei ATCC 6258.

\section{Inoculation suspensions}

The microorganism suspensions used for inoculation were prepared at $10^{6} \mathrm{cfu} / \mathrm{ml}$ concentration by diluting of the fresh cultures at McFarland 0.5 density $\left(10^{8} \mathrm{cfu} / \mathrm{ml}\right)$. It was known that there were $5 \times 10^{4} \mathrm{cfu} / \mathrm{ml}$ microorganisms in each well after inoculation.

\section{Medium}

Mueller Hinton Broth (Oxoid) liquid nutrient medium was used for diluting of microorganism suspension and two fold-dilution of the compounds. Sabouraud liquid medium (Oxoid) was used for yeast like fungi for the same purpose. 


\section{Equipment}

Falcon ${ }^{R}$ microplates which have 96 wells were used for microdilution method. Brinkmann transferpette was used for two fold-dilution of compounds in the wells.

\section{Microdilution Method}

Microdilution method was employed for antibacterial and antifungal activity tests [26]. The synthesized compound and the standarts ampicillin trihydrate and fluconazole were dissolved in DMSO at $1000 \mu \mathrm{g} / \mathrm{ml}$ concentration at the beginning. The solution of each compounds at $500-3.9 \mu \mathrm{g} / \mathrm{ml}$ were prepared in the wells by diluting with the mediums. Suspension of the microorganisms at $10^{6} \mathrm{cfu} / \mathrm{ml}$ concentration were inoculated to the twofold-diluted solution of the compounds, consequently the microorganism concentration in each well was approximately $5 \times 10^{4} \mathrm{cfu} / \mathrm{ml}$. DMSO-microorganisms mixture, the pure microorganisms, and pure media were used as control wells.

Microplates were covered and incubated at $36^{\circ} \mathrm{C}$ for $24-48$ hours. Wet cotton-wool was placed in the incubation chamber, because it should be kept sufficiently to avoid evaporation. After this period of time, evaluation of the wells was performed. The concentration of the compounds in the wells where no growth was assessed as the minimum inhibitory concentration (MIC) of the compounds. There was no inhibitory activity in the wells containing only DMSO. The microbial growth occurred, and the medium were not contaminated during the tests. The MIC values of 6-substituted-3(2H)-pyridazinone-2-yl acetyl-2-(psubstitutedbenzal)hydrazone $\mathbf{D}_{1 \mathrm{a}}-\mathbf{D}_{1 \mathrm{~d}}, \mathbf{D}_{\mathbf{2}}-\mathbf{D}_{2 \mathrm{~d}}$ derivatives were given in Table 3 .

\subsection{Molecular modelling studies}

Molecular docking studies are currently gaining much attention in the field of medicinal chemistry. The significant experimental antifungal activities of $\mathbf{D}_{2 \mathrm{a}}$ provide a hint to performing molecular docking studies to understand the protein-ligand interactions. We prepared and optimized the ligands using ChemDraw and Chem3D (2015). Molecular docking studies were performed using AutoDock (v4.2.6) [19], AutoDock Vina (v1.1.2) [27] and AutoDockTools (v1.5.6) [19]. We downloaded the crystal structure of Candida albicans lanosterol 14a-demethylase (PDB ID: 5TZ1 [28]) from RCSB Protein DataBank (http://www.rcsb.org/) [29]. We removed the water molecules and unwanted residues from the protein, added hydrogens and Gasteiger charges to it. We created grid maps of the receptor using the central coordinates of the co-crystallized ligand, VT1161, setting the grid spacing as $0.375 \AA$ and the grid box dimensions as large as to accommodate the ligands. Each ligand was docked to the receptor 50 times at full flexibility and medium exhaustiveness using Lamarckian genetic algorithm. The output conformations were clustered and analysed according to their RMSD values and docking scores. The best conformations were picked according to visual evaluation.

Acknowledgements: This project was supported by Gazi University Research Fund.

Author contributions: Concept - Z.Ö., M.A.A.; Design - Z.Ö., M.A.A., A.G.A., A.B.Ö., M.U.; Resources - A.B.Ö., B.Ö., M.U.; Supervision - M.U.; Materials - A.B.Ö., B.Ö.; Data Collection and/or Processing - Z.Ö., M.A.A., A.G.A., A.B.Ö.; Analysis and/or Interpretation - Z.Ö., A.B.Ö., B.Ö.; Literature Search - Z.Ö., M.A.A., A.B.Ö.; Writing - Z.Ö., M.A.A.; Critical Reviews - Z.Ö., M.A.A., A.G.A., A.B.Ö., B.Ö., M.U.

Conflict of interest statement: The authors declared no conflict of interest in the manuscript.

\section{Appendix A. Supplementary Material}

Supplementary material related to this article can be accessed at http://doi.org/10.35333/jrp.2019.43.

\section{REFERENCES}

[1] Hassan AS, Masoud DM, Sroor FM, Askar AA. Synthesis and biological evaluation of pyrazolo[1,5-a]pyrimidine-3carboxamide as antimicrobial agents. Med Chem Res. 2017; 26(11): 2909-2919. [CrossRef]

[2] Roca I, Akova M, Baquero F, Carlet J, Cavaleri M, Coenen S, Cohen J, Findlay D, Gyssens I, Heure OE, Kahlmeter G. The global threat of antimicrobial resistance: science for intervention. New Microbes New Infect. 2015; 6: 22-29. [CrossRef]

[3] Abdelrahman MA, Salama I, Gomaa MS, Elaasser MM, Abdel-Aziz MM, Soliman DH. Design, synthesis and 2D QSAR study of novel pyridine and quinolone hydrazone derivatives as potential antimicrobial and antitubercular agents. Eur J Med Chem. 2017; 138: 698-714. [CrossRef] 
[4] Dossaji S, Çelik Ü, Alhan E, Yıldızdaş D, Ünal İ. Infection Markers for Nosocomial Infections. J Pediatr Inf. 2008 ; 2: 12-18.

[5] Sürücü Bayar F, Bayındır Y, Işık B, Özgör D, Kayabaş Ü, Kuzucu Ç, Yılmaz S. Evaluation of Nosocomial Infections after ABO-Compatible and Incompatible Liver Transplantations. Mediterr J Infect Microb Antimicrob. 2018 ; 7.

[6] Palabıyıkoğlu İ, Bengisun JS, Oral M, Cansızoğlu F, Baran İ, Tulunay M. Reanimasyon hastalarında nozokomiyal bakteriyemi etkenleri ve kan kültürlerinde üreyen mikroorganizmalar. ADÜ J Fac Med. 2000; 1(1): 7-1.

[7] Siddiqui AA, Mishra R, Shaharyar M. Synthesis, characterizationand antihypertensive activity of pyridazinone derivatives. Eur J Med Chem. 2010; 45(6): 2283-2290. [CrossRef]

[8] Yamali C, Ozan GH, Kahya B, Çobanoğlu S, Şüküroğlu MK, Doğruer DS. Synthesis of some 3(2H)-pyridazinone and $1(2 H)$-phthalazinone derivatives incorporating aminothiazole moietyand investigation of their antioxidant, acetylcholinesterase, andbutyrylcholinesterase inhibitory activities. Med Chem Res. 2015; 24(3): 12101217. [CrossRef]

[9] Budhlakoti P, Kumar Y, Verma A, Alok S. Synthesis, antibacterial activity and molecular properties prediction of some pyridazin-3-one derivatives. Int J Pharm Sci Res. 2013; 4(4): 1524-1528. [CrossRef]

[10] Şüküroğlu M, Önkol T, Kaynak-Onurdağ F, Akalınç G, Şahin MF. Synthesis and in vitro biological activity of new 4,6-disubstituted 3(2H)-pyridazinone-acetohydrazide derivatives. Z Naturforsch. 2012; 67(5-6): 257-265. [CrossRef]

[11] Nagle P, Pawar Y, Sonawane A, Bhosale S, More D. Docking simulation, synthesis and biological evaluation of novel pyridazinonecontaining thymol as potential antimicrobial agents. Med Chem Res. 2014; 23(2): 918-926. [CrossRef]

[12] Utku S, Gökçe M, Aslan G, Bayram G, Ülger M, Emekdaş G, Şahin MF. Synthesis and in vitro antimycobacterial activities of novel 6-substituted-3 $(2 H)$-pyridazinone-2-acetyl-2-(substituted/nonsubstituted acetophenone)hydrazone. Turk J Chem. 2011; 35: 331-339. [CrossRef]

[13] Şahin MF, Badıçoglu B, Gökçe M, Küpeli E, Yeşilada E. Synthesis and analgesic and antiinflammatory activity of methyl[6-substitue-3(2H)-pyridazinone-2-yl]acetate derivatives. Arch Pharm Pharm Med. 2004; 337(8): 445-452. [CrossRef]

[14] Tiryaki D, Şüküroğlu M, Doğruer DS, Akkol E, Özgen S, Şahin MF. Synthesis of some new 2,6-disubstituted-3(2H)pyridazinone derivatives and investigation of their analgesic, anti-inflammatory and antimicrobial activities. Med Chem Res. 2013; 22(6): 2553-2560. [CrossRef]

[15] Schmidt P, Druey J. Heilmittelchemische Studien in der heterocyclischen Reihe. 10. Mitteilung. Pyridazine VII. Zur neuen Pyridazin-Synthese Methylpyridazine. Helv Chim Acta. 1954; 37(1): 134-140. [CrossRef]

[16] Zare L, Mahmoodi NO, Yahyazadeh A, Nikpassand M. Ultrasound-promoted regio and chemoselective synthesis of pyridazinones and phthalazinones catalyzed by ionic liquid [bmim]Br/ $\mathrm{AlCl}_{3}$. Ultrason Sonochem. 2012; 19(4): 740744. [CrossRef]

[17] Özdemir Z, Yılmaz H, Sarı S, Karakurt A, Şenol FS, Uysal M. Design, synthesis, and molecular modeling of new 3(2H)-pyridazinone derivatives as acetylcholinesterase/butyrylcholinesterase inhibitors. Med Chem Res. 2017; 26(10): 2293-2308. [CrossRef]

[18] Lapinski L, Nowak MJ, Fulara J, Les' A, Adamowicz L. Relation between structure and tautomerism in diazinones and diazinethlones. An experimental matrix isolation and theoretical ab initio study. J Phys Chem. 1992; 96(15): 62506254.

[19] Morris GM, Huey R, Lindstrom W, Sanner MF, Belew RK, Goodsell DS, Olson AJ. Autodock4 and AutoDockTools4: automated docking with selective receptor flexibility. J Comput Chem. 2009; 30(16): 2785-2791. [CrossRef]

[20] Morio F, Loge C, Besse B, Hennequin C, Le Pape P. Screening for amino acid substitutions in the Candida albicans Erg11 protein of azole-susceptible and azole-resistant clinical isolates: new substitutions and a review of the literature. Diagn Microbiol Infect Dis. 2010; 66(4): 373-384. [CrossRef]

[21] El-Mobayed MM, Hussein AM, Mohlhel WM. Synthesis of Some New Pyridazin-3-one Derivatives and Their Utility in Heterocyclic Synthesis. J Heterocycl Chem. 2010; 47(3): 534-537. [CrossRef]

[22] King JA. Hydrazides of pyridazonyl-substituted alkanoic acids. 1958, Pat. No: US 2832780 (https://patents.google.com/patent/US2832780A/en; Access date: 18.07.2019)

[23] Dorina M, Vasilichia A, Alina N, Calin D, Violeta V, Ionel IM. Synthesis, Stereochemical Studies and Antimycobacterial Activity of New Acetyl- Hydrazine Pyridazinones. Curr Org Synth. 2017; 14(1): 112-119. [CrossRef] 
[24] El-Hashash MA, Soliman AY, Bakeer HM, Mohammed FK, Hassan H. Synthesis of Novel Heterocyclic Compounds with Expected Antibacterial Activities from 4-(4-Bromophenyl)-4-oxobut-2-enoic Acid. J Heterocycl Chem. 2015; 52(3): 732-743. [CrossRef]

[25] Ismail MF, Shams NA, Rahman SEA, Fateen AK. Pyridazonyl acids and some derivatives. Rev Roum Chim. 1975; 24(6): 899-909.

[26] Clinical and Laboratory Standards Institute (CLSI) (formerly NCCLS), 940 West ValleyRoad, Wayne, Pennsylvania, USA, 2007.

[27] Trott O, Olson AJ. AutoDock Vina: improving the speed and accuracy of docking with a new scoring function, efficient optimization and multithreading. J Comput Chem. 2010; 31(2): 455-461. [CrossRef]

[28] Hargrove TY, Friggeri L, Wawrzak Z, Qi A, Hoekstra WJ, Schotzinger RJ, York JD, Guengerich FP, Lepesheva GI. Structural analyses of Candida albicans sterol 14 alpha-demethylase complexed with azole drugs address the molecular basis of azole-mediated inhibition of fungal sterol biosynthesis. J Biol Chem. 2017; 292(16): 6728-6743. [CrossRef]

[29] Berman HM, Westbrook J, Feng Z, Gilliland G, Bhat TN, Weissig H, Shindyalov IN, Bourne PE. The protein data bank, Nucleic Acids Res. 2000; 28(1): 235-242. [CrossRef]

This is an open access article which is publicly available on our journal's website under Institutional Repository at http://dspace.marmara.edu.tr. 